\title{
RESECTION FOR BARRETT'S MUCOSA WITH HIGH-GRADE DYSPLASIA: IMPLICATIONS FOR PROPHYLACTIC PHOTODYNAMIC THERAPY
}

Mark K. Ferguson, $\mathrm{MD}^{\mathrm{a}}$

Keith S. Naunheim, MD
Objectives: Optimal therapy for Barrett's mucosa is controversial. Photodynamic therapy has recently been introduced as a technique for eradicating Barrett's mucosa with high-grade dysplasia. We sought to determine the incidence of invasive cancer and the outcomes after resection for highgrade dysplasia and to compare these results with published results of photodynamic therapy. Methods: We performed a retrospective review of patients who underwent esophagectomy for Barrett's esophagus from 1985 to 1996 and completed a metaanalysis of published results of surgery for Barrett's esophagus with high-grade dysplasia. Results: Thirteen men and two women with a mean age of 63 years underwent resection for Barrett's esophagus with high-grade dysplasia. The operation was performed through a transhiatal approach in nine and a transthoracic approach in six patients. There was no operative mortality. The final pathologic study demonstrated dysplasia in four patients, carcinoma-in-situ in three, and invasive carcinoma in eight patients $(53 \%)$. All patients are alive and none of the patients with invasive cancer has recurrent disease. A metaanalysis of published results of 119 patients undergoing resection demonstrated an operative mortality of $2.6 \%$, an incidence of invasive cancer of $47 \%$, and a 5 -year survival in patients with invasive carcinoma of $82 \%$. Conclusions: A substantial percentage of patients with Barrett's mucosa containing foci of high-grade dysplasia have invasive carcinoma at the time of diagnosis. Resection is accompanied by a low operative risk, achieves an excellent long-term outcome, and should remain the standard therapy for Barrett's esophagus with high-grade dysplasia. (J Thorac Cardiovasc Surg 1997;114: 824-9)

0 ptimal therapy for patients with Barrett's esophagus with dysplasia is controversial. The finding of low-grade dysplasia usually is little cause for concern because the immediate risk of an invasive cancer is minimal and because the likelihood of progression to cancer, while not accurately calcu-

From the Department of Surgery, The University of Chicago, Chicago, Ill., ${ }^{a}$ and Department of Surgery, St. Louis University, St. Louis, Mo. ${ }^{\mathrm{b}}$

Read at the Seventy-seventh Annual Meeting of The American Association for Thoracic Surgery, Washington, D.C., May 4-7, 1997,

Received for publication May 6, 1997; revisions requested June 30, 1997; revisions received July 21, 1997; accepted for publication July 21, 1997.

Address for reprints: Mark K. Ferguson, MD, Chief, Section of Thoracic Surgery, Department of Surgery, The University of Chicago, 5841 S. Maryland Ave., MC5035, Chicago, IL 60637. Copyright (C) 1997 by Mosby-Year Book, Inc.

$0022-5223 / 97 \$ 5.00+0 \quad \mathbf{1 2 / 6 / 8 4 9 5 3}$ lated, is likely to be very low. In contrast, the finding of high-grade dysplasia precipitates a wide variety of responses, including increased frequency of endoscopic surveillance, esophageal resection, and, recently, photodynamic therapy (PDT). Although some centers claim to be able to reliably distinguish between patients with high-grade dysplasia who are at risk for the development of invasive cancer and those whose risk is low, ${ }^{1}$ there is no general agreement that this approach is acceptable. Instead, many groups recommend resection for healthy patients with Barrett's esophagus containing high-grade dysplasia because of the concern that a high proportion of such patients have an unsuspected invasive adenocarcinoma.

Concern over the incidence of "unnecessary" esophageal resections has stimulated the use of laser therapy, both as a thermal medium and in the form of PDT, in the eradication of Barrett's mucosa. ${ }^{2-6}$ Recent reports suggest that PDT combined with 
Table I. Results of surgical therapy for Barrett's esophagus with high-grade dysplasia

\begin{tabular}{|c|c|c|c|c|c|c|c|c|c|c|}
\hline \multirow[b]{2}{*}{ Author } & \multirow[b]{2}{*}{ Year } & \multirow{2}{*}{$\begin{array}{c}\text { No. of } \\
\text { patients }\end{array}$} & \multirow[b]{2}{*}{ Mortality } & \multicolumn{5}{|c|}{ Stage } & \multirow[b]{2}{*}{ Carcinoma } & \multirow[b]{2}{*}{ Recurrence } \\
\hline & & & & $I$ & $I I a$ & $I I b$ & $I I I$ & $I V$ & & \\
\hline DeMeester et al. ${ }^{14}$ & 1990 & 2 & $*$ & 1 & 0 & 0 & 0 & 0 & 1 & $*$ \\
\hline Altorki et al. ${ }^{15}$ & 1991 & 8 & 0 & 3 & 1 & 0 & 0 & 0 & 4 & 0 \\
\hline McArdle et al. ${ }^{16}$ & 1992 & 3 & $*$ & 2 & 0 & 0 & 0 & 0 & 2 & $*$ \\
\hline Pera et al. ${ }^{17}$ & 1992 & 18 & 0 & 6 & 2 & 1 & 0 & 0 & 9 & 2 \\
\hline Rice et al. ${ }^{18}$ & 1993 & 16 & 1 & 6 & 0 & 0 & 0 & 0 & 6 & 0 \\
\hline Levine et al. ${ }^{1}$ & 1993 & 7 & 1 & 0 & 0 & 0 & 0 & 0 & 0 & $*$ \\
\hline Peters et al. ${ }^{19}$ & 1994 & 9 & 0 & 4 & 1 & 0 & 0 & 0 & 5 & 0 \\
\hline Edwards et al. ${ }^{20}$ & 1996 & 11 & 0 & 4 & 2 & 0 & 2 & 0 & 8 & 1 \\
\hline Heitmiller et al. ${ }^{21}$ & 1996 & 30 & 1 & 8 & 4 & 0 & 1 & 0 & 13 & 2 \\
\hline $\begin{array}{l}\text { Ferguson and } \\
\text { Naunheim }\end{array}$ & 1997 & 15 & 0 & 7 & 1 & 0 & 0 & 0 & 8 & 0 \\
\hline Totals & & 119 & $3(2.6 \%)$ & 41 & 11 & 1 & 3 & 0 & $56(47 \%)$ & $5(9 \%)$ \\
\hline
\end{tabular}

intensive pharmacologic acid suppression results in the replacement of columnar mucosa with squamous mucosa and that this treatment may be relatively specific for regions of high-grade dysplasia. ${ }^{7-10}$ However, there is a strong potential for inadequate therapy of PDT for Barrett's mucosa with high-grade dysplasia because of the presence of residual columnar mucosa and, in some patients, residual high-grade dysplasia. This problem prompted us to review our results of resection for Barrett's mucosa with highgrade dysplasia. We also performed a metaanalysis of outcomes for resection to permit an accurate characterization of this treatment modality so that these results can be compared with results of PDT.

\section{Methods}

We performed a retrospective review of patients who underwent esophagectomy for Barrett's esophagus at The University of Chicago Medical Center and at St. Louis University Medical Center from 1985 through 1996. Patients were chosen for further review who had a preoperative diagnosis of high-grade dysplasia or carcinoma-insitu on the basis of endoscopic biopsy results and who had no endoscopic or histologic evidence for invasive cancer before the operation. High-grade dysplasia and carcinoma-in-situ were classified according to previously established criteria. ${ }^{11}$ Preoperative characteristics, perioperative data, and postoperative outcomes were recorded. Staging was performed according to the TNM system of the American Joint Committee on Cancer. ${ }^{12}$ Individual patient status as of April 1997 was identified by outpatient records, patient examination, or telephone interview. Data were expressed as mean \pm standard error of the mean.

We identified English language reports that described surgical therapy for Barrett's esophagus with high-grade dysplasia published from 1990 through 1996 and summarized indications for and outcome of these interventions. A metaanalysis of outcomes for surgical resection was performed and overall survival was calculated. ${ }^{13}$

\section{Results}

During the study period, 107 patients with Barrett's esophagus underwent resection. Of these, 15 were operated on for a preoperative diagnosis of high-grade dysplasia. The patients comprised 13 men and two women with a mean age of $63 \pm 3$ years (range 35 to 76 years). In contrast to the usual patient undergoing resection, these patients rarely reported dysphagia as a primary complaint, and their mean preoperative weight loss was $1.3 \pm 0.6$ $\mathrm{kg}$.

No patient received preoperative radiotherapy or chemotherapy. The operation was performed through a transhiatal approach in nine patients, through a left thoracotomy with an intrathoracic anastomosis in three, through a left thoracotomy with a cervical anastomosis in two, and by means of a modified Ivor Lewis approach with a cervical anastomosis in one patient. In all patients the entire segment of Barrett's mucosa was resected.

Reconstruction was accomplished with the stomach in 13 patients and with a colon interposition in two patients. The mean intraoperative blood loss was $715 \pm 150 \mathrm{ml}$ and the average intraoperative transfusion requirement was $1.3 \pm 0.5$ units of packed red blood cells.

No operative or hospital deaths occurred. Four patients had anastomotic leaks, all of which healed without major reoperation. The overall incidence of complications was $73 \%$ (11/15) and included pulmonary complications in four patients, cardiovascular complications in three, infectious complications in five, and other surgical complications in five patients. The mean length of postoperative hospital stay was $18.5 \pm 3.0$ days and the median length of stay was 16 days. 


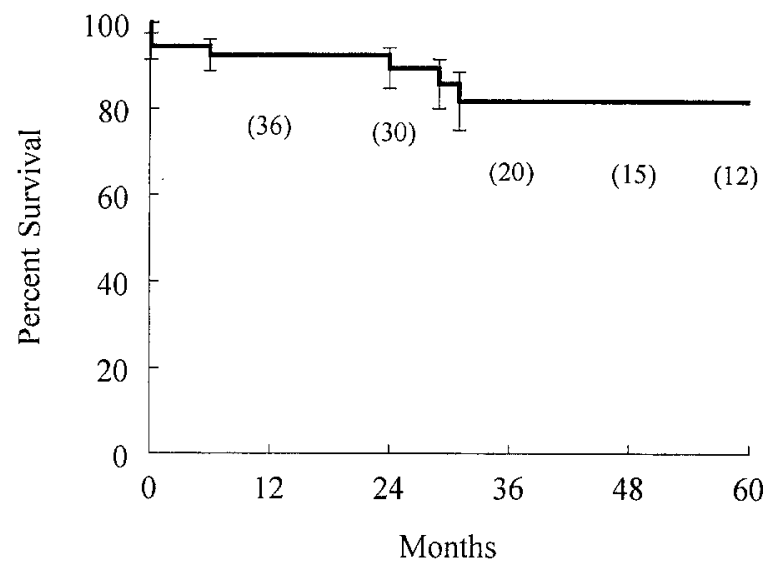

Fig. 1. Actuarial survival (including operative mortality) in patients found to have invasive adenocarcinoma after resection for high-grade dysplasia in Barrett's esophagus. Vertical bars depict standard error, and numbers in parentheses represent the number of patients at risk at each time interval. The probability of survival at 5 years is $82 \%$.

The final pathologic diagnoses in these patients revealed dysplasia only in four patients, carcinomain-situ in three, and invasive cancer in eight patients (53\%; stage $\mathrm{T} 1 \mathrm{~N} 0 \mathrm{M} 0$ in seven patients and $\mathrm{T} 3 \mathrm{~N} 0$ M0 in one patient). At a mean follow-up of $41 \pm 9$ months the median survival has not been reached and no instances of cancer recurrence have been verified.

We identified nine additional reports of surgical therapy for Barrett's esophagus with high-grade dysplasia published in English from 1990 to 1996. ${ }^{14-21}$ A total of 119 patients were analyzed, of whom $56(47 \%)$ were found to have invasive adenocarcinoma in the resected specimens (Table I). The operative mortality was $2.6 \%(3 / 114)$. Although the majority of patients had stage I cancer, $15(27 \%)$ of those patients with cancer had stage IIa or more advanced tumors. With a mean follow-up of 38 months, the cancer recurrence rate was $9 \%(5 / 53)$ among patients with invasive cancer and was $5 \%$ (2/41) among patients with stage I cancer. The 5 -year overall survival was $82 \%$ (Fig. 1).

\section{Discussion}

Barrett's esophagus is a mucosal disorder characterized by a histologic progression from metaplasia through dysplasia and finally to invasive cancer. About $10 \%$ of persons with moderate-to-severe chronic reflux symptoms have Barrett's mucosa, and about $10 \%$ of individuals with Barrett's mucosa but without invasive adenocarcinoma have dysplastic epithelium. Considering that more than 20 million individuals in North America have reflux symptoms, the problem of dysplasia is potentially large. As such, it has been studied extensively in an effort to identify markers that indicate which patients have dysplasia that is most likely to progress to invasive cancer. Such biochemical and genetic markers include the loss of O-acetylated sialomucins, the presence of sucrase isomaltase, an increase in nucleolar organizer regions, a rise in $\mathrm{G}_{2}$ phase percentages, the presence of aneuploidy, and evidence for p53 mutations. However, the promise of early detection of patients at high risk has yet to be realized..$^{22-24}$ No one has yet found a reliable means to predict which patients have dysplasia that will progress to malignant degeneration and thus should undergo prophylactic or early therapeutic intervention.

The best current means of assessing risk is the histologic or cytologic identification of high-grade dysplasia. Although expert pathologists sometimes disagree about the differentiation between low- and high-grade dysplasia and about whether high-grade dysplasia and carcinoma-in-situ can be distinguished, all agree that high-grade dysplasia is a premalignant lesion. Unfortunately, some patients with high-grade dysplasia already have invasive adenocarcinoma. The prevalence of invasive carcinoma among patients who undergo resection for high-grade dysplasia approaches 50\%, 14-21 whereas the incidence of progression from highgrade dysplasia to invasive carcinoma was reported to be about $26 \%$ during a median follow-up period of 2 years. $^{25}$ The discrepancy between these two figures may be explained in part by the fact that some patients who are referred for resection of high-grade dysplasia have other endoscopic findings such as raised mucosal lesions that increase the likelihood of finding invasive cancer. In addition, the time course of progression from dysplasia to invasive cancer is poorly understood. The histologic sampling of a resected specimen that reveals invasive cancer is more complete than that possible in endoscopic biopsies, yielding lower estimates for the frequency of progression from highgrade dysplasia to invasive carcinoma in patients undergoing surveillance than in those referred for resection.

Endoscopic ultrasonography is sometimes useful in assessing the depth of penetration of the esophageal tumors. By logical extension, endoscopic ultrasonography has found favor in some centers as a 
Table II. Results of PDT for Barrett's esophagus with HGD

\begin{tabular}{|c|c|c|c|c|c|c|c|}
\hline Author & Year & $\begin{array}{l}\text { Photoactive } \\
\text { compound }\end{array}$ & $\begin{array}{c}\text { No. of } \\
\text { patients }\end{array}$ & $\begin{array}{c}\text { Follow-up } \\
(\text { mo })\end{array}$ & Stricture & $\begin{array}{c}\text { Residual } \\
H G D\end{array}$ & $\begin{array}{c}\text { Residual } \\
\text { Barrett's } \\
\text { esophagus }\end{array}$ \\
\hline Laukka and Wang ${ }^{8}$ & 1995 & $\begin{array}{l}\text { Hematoporphyrin } \\
\text { derivative }\end{array}$ & 5 & $2-12$ & 0 & $0 / 1$ & $5 / 5$ \\
\hline Barr et al. ${ }^{9}$ & 1996 & Protoporphyrin IX & 5 & $26-44$ & 0 & $0 / 5$ & $4 / 5$ \\
\hline $\begin{array}{l}\text { Overholt and } \\
\text { Panjehpour }\end{array}$ & 1996 & Porfimer sodium & 36 & $2-62$ & 21 & $2 / 17$ & $10 / 36$ \\
\hline Totals & & & 46 & & $21(46 \%)$ & $2 / 23(9 \%)$ & $19 / 46(41 \%)$ \\
\hline
\end{tabular}

$P D T$, Photodynamic therapy; $H G D$, high-grade dysplasia.

means to assess patients with Barrett's esophagus containing areas of dysplasia. Unfortunately, the accuracy of endoscopic ultrasonography is greatest for grossly evident esophageal cancers and is poorest when relatively superficial lesions are studied. In one preliminary study of patients with Barrett's esophagus, mean mucosal thickness as measured by endoscopic ultrasonography was not different between patients with dysplastic and those with nondysplastic Barrett's mucosa. ${ }^{26}$ Another preliminary study demonstrated both overestimations and underestimations of the depth of extent of mucosal abnormalities and concluded that endoscopic ultrasonography does not reliably distinguish between benign and malignant wall thickening in patients with Barrett's mucosa. ${ }^{27}$

Because of the lack of definitive information, a number of centers recommend that patients with Barrett's esophagus containing high-grade dysplasia or carcinoma-in-situ undergo resection of the Barrett's segment because of the high risk of invasive cancer and the favorable surgical outcomes. Our metaanalysis demonstrates an operative mortality in these highly selected patients of less than $3 \%$ and a 5 -year survival of more than $80 \%$, even when the disease had advanced beyond stage $I$ in more than $25 \%$ of patients. Resection of the entire Barrett's segment also eliminates the need for routine surveillance endoscopy.

Despite these good surgical results, several centers are now involved in the use of PDT for the management of Barrett's esophagus with high-grade dysplasia or early invasive adenocarcinoma. The rationale is that PDT targets regions of high-grade dysplasia and invasive cancer, selectively eliminating threatening regions in the mucosa without the need for resection, while concurrent intense acid suppression permits resurfacing of the affected esophagus with squamous mucosa. The published results of preliminary efforts are encouraging but by no means demonstrate that PDT has a clear advantage over resection in the management of high-grade dysplasia. Among 46 cases reported to date, the followup has been relatively short, averaging less than 2 years $^{8-10}$ (Table II). The incidence of benign stricture necessitating dilation is almost $50 \%$, suggesting that functional results are not optimal despite esophageal preservation. Of greater concern is the fact that more than $40 \%$ of patients have residual Barrett's mucosa, which is theoretically at risk for the development of new regions of dysplasia. Finally, almost $10 \%$ of patients have residual areas of high-grade dysplasia, indicating that these initial attempts at eradicating columnar mucosa with highgrade dysplasia are only partially successful. As a result, patients who undergo PDT for high-grade dysplasia need to be maintained on an intense acid suppression regimen indefinitely and continue to require surveillance endoscopy at regular intervals.

What of the patients treated with PDT whose disease is understaged and who have invasive cancer or lymph node involvement, a subgroup that made up more than $25 \%$ of patients undergoing resection for high-grade dysplasia? The depth of penetration of PDT is dependent on, among other factors, the wavelength of laser energy and the techniques used to diffuse the energy into the tissues. The net result is an unpredictable and uncontrollable degree of tissue penetration, with no guarantee that the full depth of the primary tumor will be treated, much less that any effect will be evident in regional lymph nodes.

Alternatives to esophagectomy and PDT exist for management of Barrett's esophagus with high-grade dysplasia. These include eradication of Barrett's mucosa with thermal coagulation, such as electrocautery or neodymium:yttrium-aluminum-garnet laser therapy combined with intense acid suppression accomplished by fundoplication or pharmacologic means. The high frequency of nonfatal periopera- 
tive complications associated with esophagectomy and the risk of long-term disabling symptoms in some patients owing to postvagotomy syndrome, dumping, and other gastrointestinal motor disorders make the pursuit of such alternative therapies appealing. However, long-term data on the results of such treatments are currently lacking.

As a result of these findings, we conclude that resection of the Barrett's segment should be standard therapy for Barrett's esophagus with highgrade dysplasia or carcinoma-in-situ in patients with acceptable physiologic risk. This operation is performed routinely with acceptable operative mortality and excellent long-term survival. Resection eliminates the need for surveillance endoscopy and acid suppression medications in most patients. In contrast, PDT requires long-term acid suppression and continued surveillance and fails to reliably eliminate high-grade dysplasia. Optimal candidates for PDT may be those individuals who are at high risk for resection, in whom the risk of malignant degeneration may be reduced with this technique. Otherwise, until additional data and longer-term follow-up are available, the use of PDT for Barrett's esophagus with high-grade dysplasia should remain investigational.

\section{REFERENCES}

1. Levine DS, Haggitt RC, Blount PL, Rabinovitch PS, Rusch VW, Reid BJ. An endoscopic biopsy protocol can differentiate high-grade dysplasia from early adenocarcinoma in Barrett's esophagus. Gastroenterology 1993;105:40-50.

2. Brandt LJ, Kauver DR. Laser-induced transient regression of Barrett's epithelium. Gastrointest Endose 1992;38:619-22.

3. Berenson MM, Johnson TD, Markowitz NR, Buchi KN, Samowitz WS. Restoration of squamous mucosa after ablation of Barrett's esophageal epithelium. Gastroenterology 1993;104:1686-91.

4. Sampliner RE, Hixson LJ, Fennerty MB, Garewal HS. Regression of Barrett's esophagus by laser ablation in an anacid environment. Dig Dis Sci 1993;38:365-8.

5. Ertan A, Zimmerman M, Younes M. Esophageal adenocarcinoma associated with Barrett's esophagus: long-term management with laser ablation. Am J Gasteroenterol 1995;90: 2201-3.

6. Overholt BF, Panjehpour M. Barrett's esophagus: photodynamic therapy for ablation of dysplasia, reduction of specialized mucosa, and treatment of superficial esophageal cancer. Gastrointest Endosc 1995;42:64-70.

7. Regula J, MacRobert AJ, Gorchein A, Buonaccorsi GA, Thorpe SM, Spencer GM, et al. Photosensitization and photodynamic therapy of oesophageal, duodenal, and colorectal tumours using 5 aminolaevulinic acid induced protoporphyrin IX: a pilot study. Gut 1995;36:67-75.

8. Laukka MA, Wang KK. Initial results using low-dose photo- dynamic therapy in the treatment of Barrett's esophagus. Gastrointest Endosc 1995;42:59-63.

9. Barr H, Shepherd NA, Dix A, Roberts DJH, Tan WC, Krasner N. Eradication of high-grade dysplasia in columnarlined (Barrett's) oesophagus by photodynamic therapy with endogenously generated protoporphyrin IX. Lancet 1996; 348:584-5.

10. Overholt BF, Panjehpour M. Photodynamic therapy for Barrett's esophagus: clinical update. Am J Gastroenterol 1996;91:1719-23.

11. Riddell RH, Goldman H, Ransohoff DF, Appelman HD, Fenoglio CM, Haggitt RC, et al. Dysplasia in inflammatory bowel disease: standardized classification with provisional clinical applications. Hum Pathol 1983;14:931-68.

12. American Joint Committee on Cancer. Manual for staging of cancer. Philadelphia: JB Lippincott; 1988. p. 57-61.

13. Kaplan EL, Meier P. Nonparametric estimation from incomplete observations. J Am Stat Assoc 1958;53:457-81.

14. DeMeester TR, Attwood SEA, Smyrk TC, Therkildsen DH, Hinder RA. Surgical therapy in Barrett's esophagus. Ann Surg 1990;212:528-42.

15. Altorki NK, Sunagawa M, Little AG, Skinner DB. Highgrade dysplasia in the columnar-lined esophagus. Am J Surg 1991;161:97-100.

16. McArdle JE, Lewin KJ, Randall G, Weinstein W. Distribution of dysplasias and early invasive carcinoma in Barrett's esophagus. Hum Pathol 1992;23:479-82.

17. Pera M, Trastek VF, Carpenter HA, Allen MS, Deschamps C, Pairolero PC. Barrett's esophagus with high-grade dysplasia: An indication for esophagectomy? Ann Thorac Surg 1992;54:199-204.

18. Rice TW, Falk GW, Achkar E, Petras RE. Surgical management of high-grade dysplasia in Barrett's esophagus. Am J Gastroenterol 1993;88:1832-6.

19. Peters JH, Clark GWB, Ireland AP, Chandrasoma P, Smyrk TC, DeMeester TR. Outcome of adenocarcinoma arising in Barrett's esophagus in endoscopically surveyed and nonsurveyed patients. J Thorac Cardiovasc Surg 1994;108:813-22.

20. Edwards MJ, Gable DR, Lentsch AB, Richardson JD. The rationale for esophagectomy as the optimal therapy for Barrett's esophagus with high-grade dysplasia. Ann Surg 1996;223:585-91.

21. Heitmiller RF, Redmond M, Hamilton SR. Barrett's esophagus with high-grade dysplasia: an indication for prophylactic esophagectomy. Ann Surg 1996;224:66-71.

22. Iannettoni MD, Lee SS, Bonnell MR, Sell TL, Whyte RI, Orringer MB, et al. Detection of Barrett's adenocarcinoma of the gastric cardia with sucrase isomaltase and p53. Ann Thorac Surg 1996;62:1460-6.

23. Levine DS. Neoplastic progression in Barrett's esophagus: genomic instability, cell cycle abnormalities, and clonal evolution. Dis Esoph 1996;9:165-72.

24. Schneider PM, Casson AG, Levin B, Garewal HS, Hoelscher $\mathrm{AH}$, Becker K, et al. Mutations of p53 in Barrett's esophagus and Barrett's cancer: a prospective study of ninety-eight cases. J Thorac Cardiovase Surg 1996;111:323-33.

25. Levine DS, Haggitt RC, Irvine S, Reid BJ. Natural history of high-grade dysplasia in Barrett's esophagus [abstract]. Gastroenterology 1996;110:A550.

26. Srivastava AK, Vanagunas A, Kamel P, Cooper R. Endoscopic ultrasound in the evaluation of Barrett's esophagus: a preliminary report. Am J Gastroenterol 1994;89:2192-5. 
27. Falk GW, Catalano MF, Sivak MV Jr, Rice TW, Van Dam J. Endosonography in the evaluation of patients with Barrett's esophagus and high-grade dysplasia. Gastrointest Endosc 1994;40:207-12.

\section{Discussion}

Dr. Nasser K. Altorki (New York, N.Y.). Dr. Ferguson and Dr. Naunheim present us with conclusions with which we have no disagreements: (1) that high-grade dysplasia is a premalignant lesion; (2) that it is the best available marker for an associated invasive cancer; and (3) that resection yields excellent long-term results.

Despite the fact that no hospital deaths occurred in this series, esophagectomy is definitely associated with a finite mortality and a substantial morbidity, $73 \%$ in this series, with a median hospital stay of 16 days. Additionally, the patients who are discharged from the hospital without morbidity never quite regain the normal swallowing or the normal dietary habits that they would enjoy should their native esophagus be retained. Finally, almost $50 \%$ of the patients do undergo an unnecessary esophagectomy. The problem is that we cannot predict that ahead of time. A modality that may eradicate the tumor with a minimal morbidity, a short hospital stay, and retention of the native esophagus is an attractive proposition.

PDT with its limited penetration of approximately 5 $\mathrm{mm}$ to $10 \mathrm{~mm}$ may be ideally suited for the treatment of the intramucosal cancers that are often associated with high-grade dysplasia. Your data show that $75 \%$ of the tumors were $\mathrm{T} 1$ lesions, but $\mathrm{T} 1$ lesions can range from deep submucosal cancers to intramucosal cancers that breach the basement membrane but are limited by the muscularis mucosa. In our experience these account for about $75 \%$ of the actual invasive T1 lesions. Deeper tumors obviously do occur, and they are a concern because PDT would not get deep enough and the prevalence of nodal metastases would rise. However, endoscopic ultrasonography done before resection might detect those deeper tumors and obviate the need for PDT. Although strictures do occur with PDT, they are generally responsive to dilation. Furthermore, the esophagogastric anastomosis, particularly if done in the neck, will usually not require one or two sessions of dilation done after the operation.

The other issue that arises concerns the eradication of the dysplastic mucosa in patients without an associated invasive cancer. While clearly that is dramatically achieved by an esophagectomy, it seem almost tantamount to reaching for a shotgun to kill a fly. Dysplastic mucosa can be eradicated in a significant percentage of patients treated by PDT. In some cases the metaplastic columnar epithelium is buried underneath the regenerating squamous mucosa in the same manner that we sometimes see after antireflux surgery. The long-term effect of that submerged metaplastic mucosa in either case, after antireflux surgery or PDT, will obviously remain unknown for some time.

I agree with you that PDT is an investigative modality whose role has yet to be defined, but I would like to ask two questions. Do you think that PDT may be applicable in the cases of intramucosal cancers? The precedent has been set by some Japanese surgeons practicing mucosectomy for early intramucosal squamous cell cancer of the esophagus with apparently some good results. Second, do you see a role for PDT in eradicating metaplastic or dysplastic mucosa in patients without cancer at all?

Dr. Ferguson. I agree with you on most of your points. Your primary point was that one could theoretically use endoscopic ultrasonography to help decide which of the patients with Barrett's esophagus and dysplasia should receive a less aggressive form of therapy that can eradicate the mucosa versus those that need to have resectional treatment. Unfortunately, the published experience to date does not bear out that ability. The Cleveland Clinic has shown that endoscopic ultrasonography is not very accurate in assessing Barrett's mucosa. Much more experience must be gained before endoscopic ultrasonography will be useful for that.

I am hopeful for the future that we will find something other than an esophagectomy to treat these very earlystage tumors. I am also optimistic about the future of PDT. What I am concerned about is that its current use is inappropriate outside of a study and it is being adopted by many gastroenterologists as an accepted treatment for this condition. What we wanted to do was to present some of the aggregate experience to show that we are doing a very good job with our current techniques. We also wished to sound the warning that PDT may be used indiscriminately in some patients. Much more must be learned about PDT before it can be useful in a standard fashion for these patients.

Dr. Joe B. Putnam, Jr. (Houston, Tex.). Dr. Ferguson, I agree with your conclusions that esophagectomy for highgrade dysplasia is appropriate for this disease. We reviewed the cases of 29 patients over a 10 -year period with Barrett's esophagus in a nonsurveillance program; $75 \%$ had invasive carcinoma and two had positive nodes. How would you view treating patients with PDT in a surveillance program? These programs would typically have an ongoing surveillance in these individuals, the mucosal changes would be identified early, and these patients would be prime candidates. Don't you think that this would also be an appropriate population in which to study this evolving technique?

Dr. Ferguson. I agree. It would be a very good group to study as an investigational effort. Unfortunately, what we have shown here is that the current technology for PDT, including the laser wavelength, the photosensitizer, and the laser diffusion system, is not perfected, and so underpenetration is a problem in some areas. The result is incomplete eradication of the Barrett's mucosa and in complete eradication of the high-grade dysplasia. By definition, all of the patients who undergo PDT should continue with a surveillance program. That would be a good setting in which to investigate PDT. 